\title{
Perfluorooctanoic acid induces migration and invasion and inhibits apoptosis through the PI3K/AKT signaling pathway in human rhabdomyosarcoma cells
}

\author{
QIAN ZHANG $^{1 *}$, JIANAN WANG $^{1,2^{*}}$, CHEN CHEN $^{1 *}$, YI KONG $^{1,3}$, HONG YAN $^{1,4}$, \\ JINYAN DUAN $^{1}$, CHI WANG ${ }^{1}$, YINGJIAO SHA ${ }^{1}$, XINYU WEN $^{1}$ and CHENGBIN WANG ${ }^{1}$ \\ ${ }^{1}$ Chinese PLA Department of Clinical Laboratory Medicine and Chinese PLA General Hospital, \\ Medical School of Chinese PLA, Beijing $100853 ;{ }^{2}$ School of Laboratory Medicine and Life Sciences, \\ Wenzhou Medical University, Wenzhou, Zhejiang $325035 ;{ }^{3}$ Jining No. 1 People's Hospital and \\ Affiliated Jining No. 1 People's Hospital of Jining Medical University, Jining Medical University, \\ Jining, Shandong 272000; ${ }^{4}$ Nanjing Chest Hospital, Jiangsu, Nanjing, Jiangsu 210029, P.R. China
}

Received February 21, 2019; Accepted June 27, 2019

DOI: 10.3892/or.2019.7265

\begin{abstract}
The present study aimed to investigate the effects of perfluorooctanoic acid (PFOA) on tumor cell migration, invasion and apoptosis by activation of the PI3K/AKT signaling pathway in human rhabdomyosarcoma (RMS). PFOA is a persistent, synthetic organic environment pollutant, which has been previously associated with multiple diseases, including cancer. The present study aimed to confirm whether PFOA can elicit cell growth in the RD subline of RBS. RD cells were treated with different concentrations of PFOA. Cell proliferation was evaluated using Cell Counting Kit-8 and cell cycle assays. Cell migration and invasion were determined using wound healing and Transwell assays. Apoptotic rates were estimated by Annexin V-FITC/propidium iodide staining. The expression levels of vimentin, serum/glucocorticoid-regulated kinase 1 (SGK1), cyclin E2, cyclin dependent kinase (CDK)2, p53, p21, p27, phosphatidylinositol-3 kinase (PI3K) and protein kinase B (AKT), and apoptosis-associated genes and proteins (including Bcl-2 and Bax) were detected by reverse transcription-PCR and western blot analyses. The results showed that PFOA significantly promoted RD cell proliferation, migration and invasion and significantly inhibited RD cell apoptosis. Exposure to PFOA also induced the expression of vimentin, SGK1, cyclin E2, CDK2, AKT, PI3K and Bcl-2, but suppressed
\end{abstract}

Correspondence to: Dr Chengbin Wang, Chinese PLA Department of Clinical Laboratory Medicine and Chinese PLA General Hospital, Medical School of Chinese PLA, 28 Fuxing Road, Beijing 100853, P.R. China

E-mail: wangcbin301@163.com

${ }^{*}$ Contributed equally

Key words: rhabdomyosarcoma cells, PI3K/AKT signaling pathway, carcinogen the expression of Bax in the RD cells. The treatment of RD cells with BEZ235, a PI3K inhibitor, antagonized the effects of PFOA on metastatic formation and apoptosis. The results obtained show that the PI3K/AKT signaling pathway is implicated in mediating the pro-neoplastic effects of PFOA. The data suggests that PFOA is a carcinogen capable of promoting RD cell migration and invasion and inhibiting apoptosis through the PI3K/AKT signaling pathway.

\section{Introduction}

Perfluorooctanoic acid (PFOA) is a man-made, synthetic chemical and persistent organic pollutant, which has been detected in several settings, including non-stick cookware, cosmetics, bioaccumulation in food chains (1) and drinking water (2). PFOA has also been detected in the blood in several industrialized countries. Exposure to PFOA may be associated with several adverse effects, and recent epidemiological studies have linked its toxicity to tumorigenic processes in the liver, pancreas, breast and testicles (3-6).

The epithelial-mesenchymal transition (EMT) is a complex cellular mechanism involved in tumor cell motility, invasion and the formation of metastases (7). The downregulation or upregulation of cell surface markers, including E-cadherin, vimentin and serum/glucocorticoid-regulated kinase 1 (SGK1), are some of the important alterations occurring during metastatic progression (8-10). EMT comprises two critical steps: Loss of E-cadherin and acquisition of vimentin. E-cadherin often functions as a tumor suppressor, inhibiting cancer cell invasion and metastases (11), whereas vimentin is a major constituent of the intermediate filament family of proteins, and its overexpression is associated with tumor growth and invasion and poor prognosis in certain types of cancer (12). Immunohistochemical testing for vimentin is positive in rhabdomyosarcoma (RMS) (13). In a recent study, SGK1 was identified and characterized as a tumor-promoting gene, with its inhibition significantly attenuating in vitro and in vivo EMT and metastases formation in prostate cancer, and 
its overexpression promoting the invasion and migration of the tumor cells (10).

Tumor development is driven by a series of genetic alterations caused by abnormal cell division cycles that gradually transform normal cells into cancer cells. In the G1 phase, in which cells respond to external signals, developmental changes in the cell division cycle may affect cell proliferation and differentiation. Studies of early embryonic cancer cells have shown that differentiation can be rapidly induced in the G1 phase but not in the $S$ phase (14). In several studies, the length of the G1 phase is significantly associated with maintenance of cell differentiation. The short embryonic cycle is characterized by a lack of active cyclin-dependent kinase (CDK) inhibitors, and the increased levels of CDKs and cyclins, particularly CDK2-cyclin E (15-17).

The phosphatidylinositol-3 kinase (PI3K)/protein kinase B (AKT) pathway is often activated in various types of cancer (18). Activation of the PI3K/AKT pathway controls several hallmarks of cancer, including cell cycle, survival, metabolism and motility, which serve important roles in the regulation of EMT-associated cell surface markers in cancer cells (19). Apoptosis is a conserved and regulated mechanism of physiological cell death, and the inhibition of apoptosis may induce cancer cell growth. Evidence has confirmed that the $\mathrm{PI} 3 \mathrm{~K} / \mathrm{AKT}$ pathway is implicated in the regulation of cellular processes, including cell proliferation, invasion, cell cycle progression and apoptosis (20). Therefore, the PI3K/AKT signaling pathway serves an important role in cancer progression (19).

RMS is a soft tissue sarcoma of skeletal muscle phenotype originating from a primitive mesenchymal cell. It develops during childhood, primarily in those $<5$ years of age. The incidence of RMS is inferior to that of malignant fibrous histiocytoma and liposarcoma, ranking third of soft tissue sarcomas. The mechanisms by which PFOA affects muscle tissues with abundant blood supply can be examined in animal and cell models. RD cells are a subline of RMS. Our studies have shown that PFOA is capable of transforming RD cells into a malignant phenotype by altering vimentin and SGK1 proteins and inducing cell migration and invasion.

In the present study, the potential tumorigenic activity of PFOA in RD cells was evaluated. Cell viability, migration, invasion and apoptosis were evaluated to investigate the effects of PFOA exposure on cell proliferation. To better evaluate the response of RD cells to PFOA exposure, EMT and apoptosis-related proteins E-cadherin, vimentin, SGK1, Bax, Bcl-2, PI3K and AKT were examined. To investigate the role of the PI3K/AKT signaling pathway in PFOA-affected RD cells, a PI3K inhibitor was used. The findings may help to disclose the mechanisms underlying the effects of PFOA on the development of RMS.

\section{Materials and methods}

Reagents and antibodies. PFOA (purity $\geq 96 \%$ ) was obtained from Sigma-Aldrich; Merck KGaA (St. Louis, MO, USA). Fetal bovine serum (FBS), penicillin-streptomycin, Dulbecco's phosphate-buffered saline (PBS), and Dulbecco's modified Eagle's medium (DMEM) were used from Gibco (Thermo Fisher Scientific, Inc., Waltham, MA, USA). Trypsin solution $(0.05 \%)$ was purchased from Gibco (Thermo Fisher Scientific, Inc., Waltham, MA, USA). Propidium iodide (PI) was purchased from Abcam (Cambridge, UK) and the Annexin V-FITC Apoptosis Detection kit was purchased from BD Biosciences (San Diego, CA, USA). All antibodies used for western blot analysis were purchased from Cell Signaling Technology, Inc. (Beverly, MA, USA). BEZ235 (Selleck Chemicals, Houston, TX, USA) was used for inhibiting the activation of PI3K.

Cell culture. The RD human embryonal RMS cell line was provided by the Institute of Laboratory Animal Science, Chinese Academy of Medical Sciences and Comparative Medicine Center, Peking Union Medical College (Beijing, China). The cells were maintained in DMEM containing $100 \mathrm{U} / \mathrm{ml}$ of streptomycin and $100 \mathrm{U} / \mathrm{ml}$ of penicillin supplemented with $10 \%$ FBS and were cultured in a humidified atmosphere of $5 \%$ carbon dioxide $\left(\mathrm{CO}_{2}\right)$ at $37^{\circ} \mathrm{C}$. The RD cells were maintained as a monolayer in $25-\mathrm{cm}^{2}$ polypropylene flasks with the same growth, split 1:5 every 2-3 days, and were subcultured until they reached $90 \%$ confluence prior to being harvested with trypsin.

PFOA exposure. PFOA was dissolved in sterile deionized water to obtain a $10-\mathrm{mM}$ stock solution and added to the culture medium with $1 \%$ FBS to produce different concentrations. The RD cells were plated in 96-well tissue culture plates $\left(1 \times 10^{5}\right.$ cells/well $)$ for $12 \mathrm{~h}$. The culture medium was then discarded, and the cells were incubated with medium with $1 \%$ FBS containing PFOA for 36 and $72 \mathrm{~h}$ at $37^{\circ} \mathrm{C}$ and subsequently washed twice with PBS.

\section{Cell viability assay with Cell Counting Kit-8 (CCK-8). CCK-8} (Dojindo Molecular Technologies, Inc., Kumamoto, Japan) was used to measure RD cell viability. The RD cells were treated with different PFOA concentrations $(0,1,10,50,100$, 500 and $1,000 \mu \mathrm{M}$ ) for 36 and $72 \mathrm{~h}$ and subsequently treated with $50 \mu \mathrm{M} / 1$ PFOA and different concentrations of BEZ235 $(0,10,50$ and $100 \mathrm{nM})$ for $72 \mathrm{~h}$. Following incubation for the indicated time, $10 \mu \mathrm{lCCK}-8$ solution was added to each well and incubated for $2 \mathrm{~h}$ at $37^{\circ} \mathrm{C}$ to separately examine the effects of PFOA, and PFOA and BEZ235 on RD cell proliferation. The absorbance in each well was measured with a Multiskan GO spectrophotometer (Thermo Fisher Scientific, Inc.) at $450 \mathrm{~nm}$. Three independent experiments were performed in triplicate. The rate of cell growth inhibition was calculated as an absorbance fraction compared with the control.

Cell cycle analysis. The RD cells were seeded into 6-well plates $\left(2.5 \times 10^{5}\right.$ cells/well $)$ for $12 \mathrm{~h}$. The cells were treated with PBS, PFOA, PFOA and BEZ235, or BEZ235, as described above, for $72 \mathrm{~h}$, harvested in a single cell suspension, fixed in $66 \%$ ethanol, stored at $4^{\circ} \mathrm{C}$ for $2 \mathrm{~h}$, rehydrated with PBS, stained with PI and incubated with RNase for $30 \mathrm{~min}$. The PI fluorescence intensity was determined via FL2 flow cytometry and $488 \mathrm{nM}$ laser excitation, with an excitation maximum of $493 \mathrm{~nm}$ and emission maximum of $636 \mathrm{~nm}$.

Wound healing migration assays. Cell migration was assessed using wound healing assays. The RD cells were seeded in 
12 -well plates for $24 \mathrm{~h}$ and cultured to $\sim 80 \%$ confluence. The cells in the monolayer were subsequently scratched with a $10-\mu \mathrm{l}$ pipette tip, washed twice with DMEM with 2\% FBS to remove the detached cells, and treated with PFOA at $0 \mu \mathrm{M} / 1$, PFOA at $50 \mu \mathrm{M} / 1$, or PFOA at $50 \mu \mathrm{M} / 1$ and BEZ235 at $50 \mathrm{nM} / 1$ for 0 and $48 \mathrm{~h}$. The wounded areas were observed under an inverted microscope (Olympus CKX41), and the cell migration count was determined in four fields using software (ImageJ $1.44 \mathrm{p}$ ) (NIH, Bethesda, MA, USA).

Transwell cell invasion assays. The RD cells were seeded in 12-well culture plates at a density of $4 \times 10^{5}$ cells/well and incubated with PFOA at $0 \mu \mathrm{M} / 1$, PFOA at $50 \mu \mathrm{M} / 1$, or BEZ235 at $50 \mu \mathrm{M} / 1$ and PFOA at $50 \mu \mathrm{M} / 1$ at $37^{\circ} \mathrm{C}$ in a $5 \% \mathrm{CO}_{2}$-humidified atmosphere for $48 \mathrm{~h}$, with completely untreated cells used as a negative control. The cells were then suspended in serum-free DMEM and plated at a density of $2 \times 10^{5}$ cells/well in the upper chamber of Transwell plates with polycarbonate membranes (8.0-mm pore size) and diluted Matrigel coating (Corning, New York, NY, USA). Complete medium (10\% FBS DMEM; $600 \mathrm{ml}$ ) was added to the lower chamber. Following incubation for $24 \mathrm{~h}$ at $37^{\circ} \mathrm{C}$ in a $5 \% \mathrm{CO}_{2}$-humidified atmosphere, cells that had passed through the filters into the bottom wells were fixed in $100 \%$ methanol for $30 \mathrm{~min}$ at $4^{\circ} \mathrm{C}$ and stained with $0.5 \%$ crystal violet for $15 \mathrm{~min}$ at $37^{\circ} \mathrm{C}$. The number of cells was counted, as previously described, using an ImageXpress Micro XLS Widefield High-Content analysis system (Molecular Devices, LLC, Sunnyvale, CA, USA) and SoftMax Pro 6 software (Molecular Devices, LLC).

Analysis of apoptosis. The RD cells were seeded in 6-well plates (1x10 ${ }^{5}$ cells per well) for $24 \mathrm{~h}$ and treated with $50 \mu \mathrm{m} / 1$ PFOA, $50 \mu \mathrm{M} / 1$ PFOA and $50 \mathrm{nM} / 1$ BEZ235, or $50 \mathrm{nM} / 1$ BEZ235 for $72 \mathrm{~h}$ (with completely untreated control cells separately), washed twice in cold PBS and resuspended in binding buffer. The Annexin-V-FITC detection kit $(10 \mu \mathrm{l})$ and PI (10 $\mu \mathrm{l})$ were added and incubated for $20 \mathrm{~min}$ at room temperature in the dark. Following incubation, $400 \mu \mathrm{l}$ binding buffer was added, and the cells were immediately analyzed with a FACScan flow cytometer (FACSCalibur; BD Biosciences) using CellQuest software ${ }^{\mathbb{C}} 2002$ (BD Biosciences).

$R N A$ extraction, and reverse transcription-quantitative $P C R$ (RT-qPCR) analysis. RT-qPCR analysis was performed to detect the mRNA expression levels of E-cadherin, vimentin, SGK1, cyclin E2, CDK2, p21, p27, p53, Bcl-2, Bax, PI3K and AKT, with glyceraldehyde 3-phosphate dehydrogenase (GAPDH) as a housekeeping gene. The RD cells were treated with $0 \mu \mathrm{M} / 1$ PFOA, $50 \mu \mathrm{M} / 1$ PFOA, or $50 \mu \mathrm{M} / 1$ PFOA and $50 \mathrm{nM} / 1$ BEZ235 for $72 \mathrm{~h}$. Total RNA was extracted with TRIzol reagent according to the manufacturer's protocol (Thermo Fisher Scientific, Inc.). Following this, $1 \mathrm{ml}$ of RNA was used for concentration determination with a NanoDrop OneC Microvolume UV-Vis Spectrophotometer with Wi-Fi. Total RNA reverse transcription was performed with random hexamers using a reverse transcription kit (Takara Bio, Inc., Otsu, Japan), $1 \mu$ l RNA, $4 \mu 1$ 5X reaction buffer, $1 \mu$ l Ribolock RNA inhibitor, $2 \mu 110$ mM dNTP mix, $1 \mu 1$ RevertAid M-MulV reverse transcriptase and $11 \mu \mathrm{l}$ water. The RNA reverse transcription conditions were as follows: $25^{\circ} \mathrm{C}$ for $5 \mathrm{~min}, 45^{\circ} \mathrm{C}$ for $60 \mathrm{~min}$ and $70^{\circ} \mathrm{C}$ for $5 \mathrm{~min}$. Real-time qPCR analysis was subsequently performed to determine target gene expression using specific primers (Table I) and the SYBR-Green kit (Takara Bio, Inc.). The qPCR conditions included an initial denaturation at $95^{\circ} \mathrm{C}$ for $10 \mathrm{~min}$, followed by a 40 -cycle amplification consisting of denaturation at $95^{\circ} \mathrm{C}$ for $10 \mathrm{sec}$, annealing at $60^{\circ} \mathrm{C}$ for $20 \mathrm{sec}$ and extension at $72^{\circ} \mathrm{C}$ for $30 \mathrm{sec}$. This was followed by melting curve analysis to verify the qPCR product identity. The relative mRNA expression levels were evaluated using the $2^{-\Delta \Delta C q}$ method (21). GADPH was used as a reference gene.

Western blot analysis. The RD cells were seeded in a $100-\mathrm{mm}^{2}$ dish ( $3 \times 10^{5}$ cells/dish), adhered for $24 \mathrm{~h}$, and treated with $0 \mu \mathrm{M} / 1$ PFOA, $50 \mu \mathrm{M} / 1$ PFOA, $50 \mu \mathrm{M} / 1$ PFOA and $50 \mathrm{nM} / 1$ BEZ235, or $50 \mathrm{nM} / 1$ BEZ235 for $72 \mathrm{~h}$. The cell proteins were lysed using RIPA Lysis and Extraction Buffer (Thermo Fisher Scientific, Inc.), centrifuged at $12,000 \mathrm{x} \mathrm{g}$ at $4^{\circ} \mathrm{C}$ for $30 \mathrm{~min}$ to retrieve proteins in the supernatant, and collected and quantified using the Bicinchoninic Acid Protein Assay kit. Equal quantities of protein $(30 \mathrm{mg}$ ) from each sample were loaded for $12 \%$ of SDS-PAGE and transferred onto a polyvinylidene difluoride membrane. Following blocking with 5\% skim milk at room temperature for $1 \mathrm{~h}$, the membranes were subsequently probed with a primary antibody at $4{ }^{\circ} \mathrm{C}$ overnight. The antibodies used were as follows: Rabbit anti-AKT (cat no. 4685S), PI3K p85 (cat. no. 4257T), E-cadherin (cat. no. 3195T), vimentin (cat. no. 5741T), SGK1 (cat. no. 12103S), Bcl-2 (cat. no. 4223T), Bax (cat. no. 5023T), cyclin E2 (cat. no. 4132T), CDK2 (cat. no. 2546T), P53 (cat. no. 2527T), P21 (cat. no. 2947T) and P27 (cat. no. 3686T), and mouse anti-GADPH (cat. no. 51332S) and diluted at 1:1,000. The membranes were washed for $10 \mathrm{~min}$ with TBS three times and incubated with peroxidase-labeled goat anti-rabbit and anti-mouse secondary antibody at room temperature for $1 \mathrm{~h}$. The membranes were subsequently washed for $10 \mathrm{~min}$ with TBST three times, and the protein bands were visualized using an ECL western blotting kit according to the manufacturer's instructions. Densitometry was performed using Quantity One software 4.4.0 (Tanon 5500; Tanon, Shanghai, China).

Animal experiments. Male Balb/c mice (aged 5-6 weeks, 15-20 g) were purchased from Beijing QuantoBio Biotechnology Co., Ltd. (Beijing, China). The feeding environment requires a temperature of $18-29^{\circ} \mathrm{C}$, a daily temperature difference of less than $3^{\circ} \mathrm{C}$, a relative humidity of $40-70 \%$, fresh air replacement 10 times/h, the airflow speed of less than $18 \mathrm{~m} / \mathrm{s}$, a pressure difference of $25 \mathrm{~Pa}$, a cleanliness of 10,000 , a nitrogen concentration of $15 \mathrm{mg} / \mathrm{m}^{3}$, a noise of less than $60 \mathrm{~dB}$, and the illumination of 150-300 Lux, the clean water from the filter, add hydrochloric acid, and the $\mathrm{pH}$ 2.8-3.0, changed twice a week, and feed aseptic, high nutrition, added daily and viewed, and all experimental manipulations were performed as previously described (22). Briefly, the mice were divided into three groups, with six animals in each group. Their right/left forelimb was subcutaneously injected with $1 \times 10^{7} /$ cells, and purified water + PBS, purified water + PFOA (100 mg/day), and purified water + PFOA (100 mg/day) + BEZ235 (50 mg/day) were separately administered for 30 days. The doses of PFOA and BEZ235 were selected based on earlier studies $(22,23)$. All 
Table I. Primer sequences used for PCR.

\begin{tabular}{lll}
\hline Gene & \multicolumn{1}{c}{ Forward (5'-3') } & \multicolumn{1}{c}{ Reverse $\left(5^{\prime}-3^{\prime}\right)$} \\
\hline E-cadherin & TGGAGGAATTCTTGCTTTGC & CGCTCTCCTCCGAAGAAAC \\
Vimentin & GGCTCGTCACCTTCGTGAAT & GAGAAATCCTGCTCTCCTCGC \\
SGK1 & AGGATGGGTCTGAACGACTTT & GCCCTTTCCGATCACTTTCAAG \\
Cyclin E2 & GGCCTATATATTGGGTTGGCG & ACGGCTACTTCGTCTTGACA \\
P21 & TCAGAGGAGGTGAGAGAGCG & ACATGGCGCCTGCCG \\
P27 & GTTCACGATGTCCGACGAGG & ATCCACTTGCAGACCGCTT \\
CDK2 & ATCTTTGCTGAGATGGTGACTCG & TAAAATCTTGCCGGGCCCAC \\
P53 & CCTGGATTGGCCAGACTGC & TCATCCATTGCTTGGGACGG \\
Bcl-2 & ATGTGTGTGGAGAGCGTCAA & GAGACAGCCAGGAGAAATCAA \\
Bax & ACGAACTGGACAGTAACATGGAG & CAGTTTGCTGGCAAAGTAGAAAAG \\
PI3K & AGATCGCTCTGGCCTCATTG & TCCAGGTCATCCCCAGAGTT \\
AKT & GAAGTCAAAGGGGCTGCCT & TACTCCCCTCGTTTGTGCAG \\
GADPH & ACCCATCACCATCTTCCAGGAG & GAAGGGGCGGAGATGATGAC \\
\hline
\end{tabular}

SGK1, serum/glucocorticoid-regulated kinase; CDK, cyclin-dependent kinase; PI3K, phosphatidylinositol-3 kinase; AKT, protein kinase B.

animal treatments were approved by the Ethics Committee of the Experimental Animal Center and by the Chinese Academy of Military Medical Sciences (permit no. SCXK-2015-0002), in accordance with the guiding principles for the use of animals in toxicology, adopted by the Society of Toxicology in 1989.

Statistical analysis. All experiments were performed a minimum of three times unless otherwise stated. Data are expressed as the mean \pm standard deviation. The statistical significance of experiments was assessed using one-way ANOVA (parametric) or Kruskal-Wallis (non-parametric) and a multiple comparisons test, and the LSD post hoc test was used following ANOVA. $\mathrm{P}<0.05$ was considered to indicate a statistically significant difference. All statistical analyses were performed with SPSS 12.0 (SPSS, Inc.), and the graphs were produced using GraphPad Prism 7 (GraphPad Software, Inc., San Diego, CA, USA).

\section{Results}

PFOA exposure elicits RD cell proliferation, migration and invasion. To investigate the effect of PFOA in the development of human RMS, RD cells were treated with different doses of PFOA for 36 or $72 \mathrm{~h}$. A CCK-8 assay was initially used to evaluate the effect of different doses of PFOA on the RD cell survival ratio. Exposure to PFOA at 50 and $100 \mu \mathrm{M}$ for $72 \mathrm{~h}$ was found to increase the production of CCK-8 $(\mathrm{P}<0.05)$ compared with that in other groups after $72 \mathrm{~h}$, but no cells were found to proliferate after $36 \mathrm{~h}$ (Fig. 1A and B). By contrast, exposure to 500 and $1,000 \mu \mathrm{M}$ concentrations inhibited cell viability at 36 and $72 \mathrm{~h}$ (Fig. $1 \mathrm{~A}$ and $\mathrm{B}$ ). The ability of PFOA to elicit RD cell migration and invasion was further examined by selecting a PFOA concentration of $50 \mathrm{mM}$ for all subsequent experiments. Cell migration was investigated by treating RD cells with PFOA for $48 \mathrm{~h}$ in wound healing assays. In the area of wound healing, cell migration was significantly accelerated in RD cells treated with PFOA for $48 \mathrm{~h}$ compared with that in PBS-treated controls ( $\mathrm{P}<0.05$; Fig. $1 \mathrm{C}$ and $\mathrm{D})$. A Transwell assay was used to examine cell invasion of the RD cells treated with PFOA for $48 \mathrm{~h}$, as shown in Fig. 1E and F. PFOA exposure for $48 \mathrm{~h}$ was found to significantly induce RD cell invasion. The results confirmed that PFOA exposure stimulated proliferation, migration and invasion in RD cells.

PFOA-induced upregulation of EMT-related markers in RD cells. EMT is one of the key events during tumor invasion and migration in several types of human cancer. It elicits changes in several molecular pathways and networks, with loss of the expression of E-cadherin and the overexpression of vimentin and SGK1 as critical steps driving the developmental process in human cancer $(9,10,24)$. To determine whether PFOA exposure elicited EMT, the expression levels of E-cadherin, vimentin and SGK1 were investigated. Based on the RT-qPCR and western blot analyses, PFOA exposure resulted in significant increases in the expression of vimentin and SGK1 at the mRNA and protein levels, respectively (Fig. 2A-E). However, despite five sets of primers designed, E-cadherin was not detected at either the mRNA or protein level. This suggests that PFOA exposure may promote EMT in RD cells.

PFOA inhibits apoptosis in RD cells. To investigate the effect of PFOA exposure on cell apoptosis, which was quantitatively determined by Annexin V-FITC and PI fluorescence staining, flow cytometry was conducted. Following treatment with $50 \mu \mathrm{M} / 1$ PFOA for $72 \mathrm{~h}$ (Fig. 3A), the percentage of total cell death (early and late apoptosis + necrosis) was significantly decreased from 13.74 to $9.86 \%$ ( $\mathrm{P}<0.05$; Fig. 3B). To further investigate the apoptotic mechanism, the intracellular apoptotic signaling pathway was examined in RD cells following treatment with $50 \mu \mathrm{M} / 1$ of PFOA for $72 \mathrm{~h}$. The results showed that the mRNA and protein expression levels of Vcl-2 were significantly upregulated, whereas that of Bax was significantly downregulated (Fig. 3C-G). These data suggest that PFOA may inhibit RD cell apoptosis by inhibiting the intracellular apoptotic signaling pathway. 

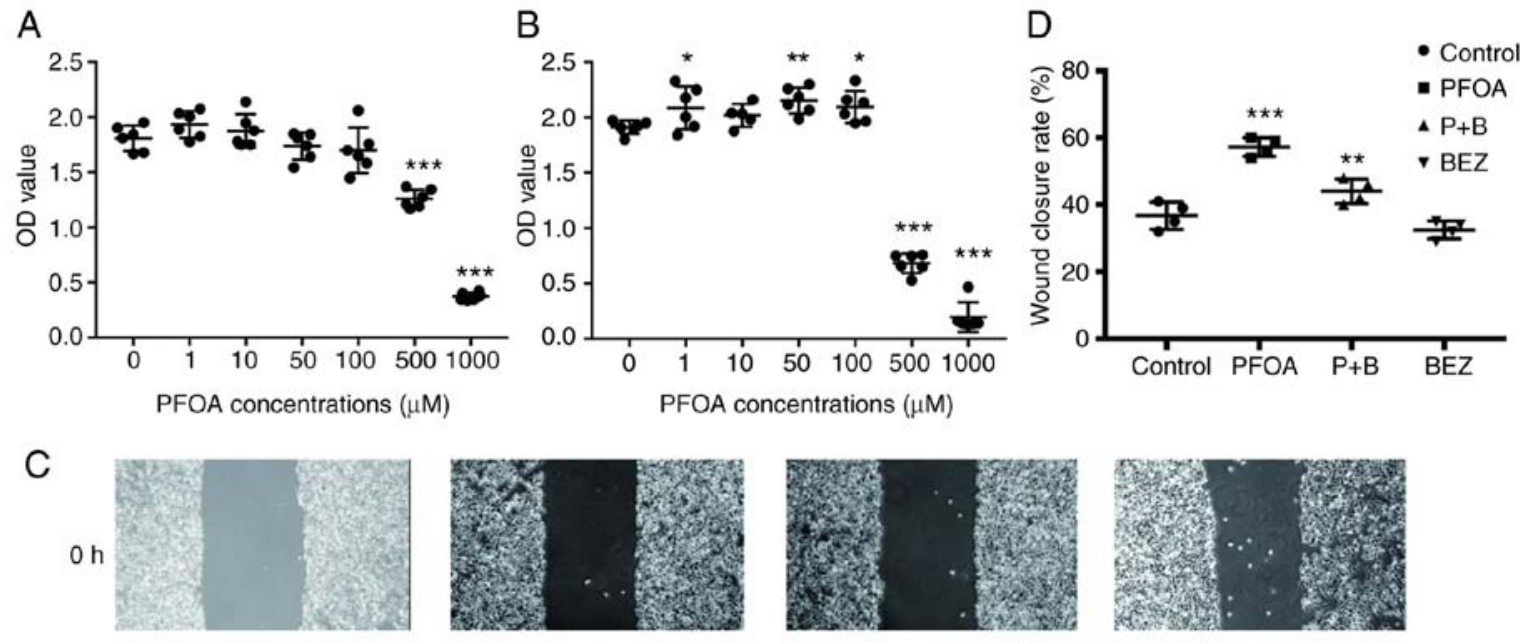

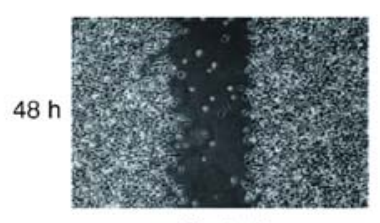

Control

\section{E}

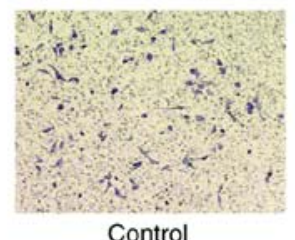

Control

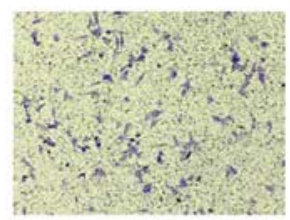

$\mathrm{PFOA}+\mathrm{BEZ}$

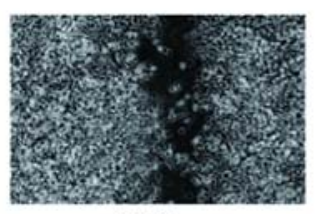

PFOA
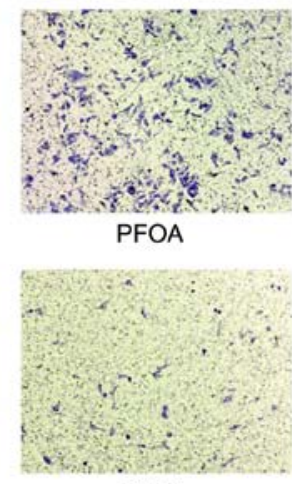

BEZ

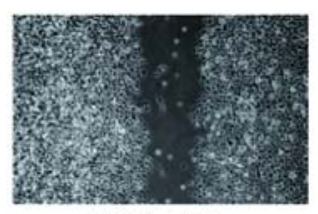

$\mathrm{PFOA}+\mathrm{BEZ}$

F

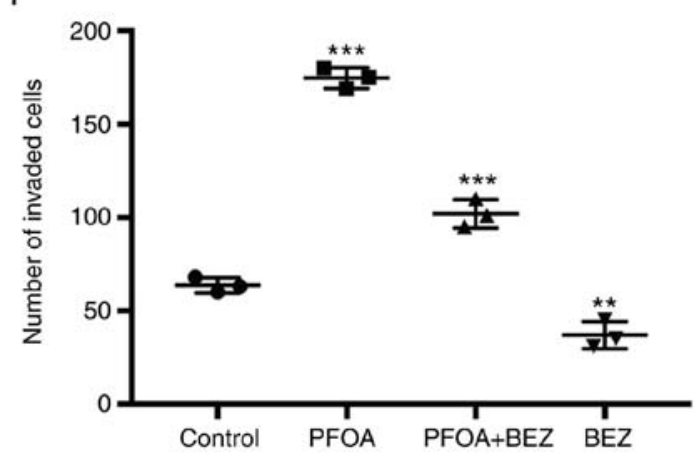

Figure 1. PFOA elicits RD cell proliferation, migration and invasion. (A) RD cells treated with different PFOA concentrations for 36 h. (B) RD cells treated with different PFOA concentrations for $72 \mathrm{~h}$. Cell viability was assessed using a Cell Counting Kit- 8 assay. (C) Wound healing assays were performed in RD cells treated with PBS, PFOA, PFOA + BEZ235, and BEZ235 for $48 \mathrm{~h}$. (D) Images of the wound healing assay. (E) In the Transwell assay, RD cells were treated with PBS, PFOA, PFOA + BEZ235, and BEZ235 for 48 h. (Magnification, $\mathrm{x} 40$ ). (F) Quantification of results of the Transwell assay. Control, PBS treatment. ${ }^{*}<0.05$, ${ }^{* *} \mathrm{P}<0.01$ and ${ }^{* * *} \mathrm{P}<0.001$ vs. control (PBS-treated). PFOA, perfluorooctanoic acid; PBS, phosphate-buffered saline; BEZ, BEZ235; P+B, PFOA + BEZ235.

PFOA can alter the proportion of the three RD cell cycle phases and expression of associated $m R N A$ and protein levels. The present study found that treatment with $50 \mu \mathrm{M}$ of PFOA may elicit RD cell proliferation. PI staining and flow cytometry were used to investigate the effect of PFOA exposure on $\mathrm{RD}$ cells and cell cycle phase proportions. The proportion of cells in each cell cycle phase after $72 \mathrm{~h}$ of PFOA exposure are shown in Fig. 4A and B. The results showed that, following the addition of PFOA, the proportion of cells in the $S$ phase was reduced and that in the G1/G2 phase was increased. The expression of cell cycle-associated mRNAs and proteins were subsequently examined, and cyclin E2 and CDK2 were found to increase at the mRNA and protein levels following administration of FPOA (Fig. 4C-G).

PFOA exposure induces RD cell proliferation, migration and apoptosis by activation of PI3K/AKT signaling pathway. To investigate the mechanism induced by PFOA exposure, the activity of the oncogenic PI3K/AKT pathway was examined. The results showed that, compared with that in the control group, PFOA exposure increased RD expression of PI3K and AKT at mRNA and protein levels after $72 \mathrm{~h}$ (Fig. 5A-E). This suggested that PFOA enhances proliferation, migration and invasion and inhibits apoptosis by promoting PI3K/AKT activity in RD cells. To confirm this hypothesis, the preferential BEZ235 concentration was initially selected using a CCK8 assay (Fig. 5F) and subsequently compared with single PFOA exposure and combined PFOA and BEZ235 exposure in RD cells. The results showed that the double PFOA and BEZ235 exposure impaired cell proliferation (Fig. 5G), migration (Fig. 1C) and invasion (Fig. 1E), in addition to EMT (Fig. 2A-E), apoptosis (Fig. 3A-G) and cell cycle (Fig. 4A-G) following exposure to PFOA alone.

In vivo experiment confirmation that PFOA can elicit $R D$ cell proliferation. Our studies had comformed that PFOA promotes 

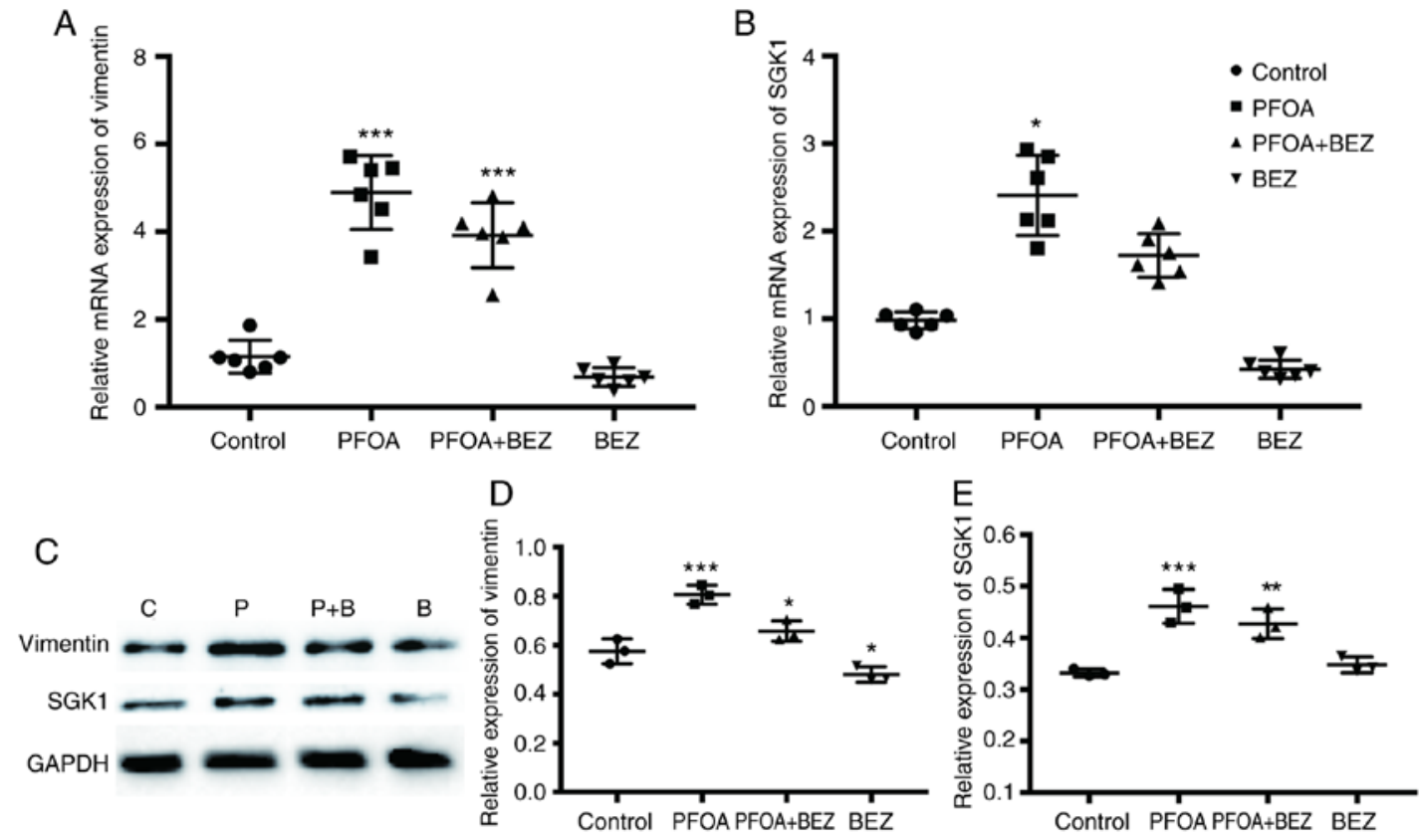

Figure 2. Effects of PFOA treatment on the expression of vimentin and SGK1 in RD cells. Reverse transcription-quantitative polymerase chain reaction analysis of (A) vimentin and (B) SGK1 in PBS-, PFOA-, PFOA + BEZ235-, and BEZ235-treated RD cells. Expression data is normalized to GADPH. (C) Expression levels of vimentin and SGK1 were assessed, with GADPH used as an internal control, by western blotting. (D and E) Quantitative measurement of vimentin and SGK1 band densities. Data are presented as the mean $\pm \mathrm{SD}$. ${ }^{*} \mathrm{P}<0.05,{ }^{* *} \mathrm{P}<0.01$ and ${ }^{* * *} \mathrm{P}<0.001$ vs. control (PBS-treated). PFOA, perfluorooctanoic acid; SGK1, serum/glucocorticoid-regulated kinase 1; PBS, phosphate-buffered saline; BEZ, BEZ235; P+B, PFOA + BEZ235; C, control.
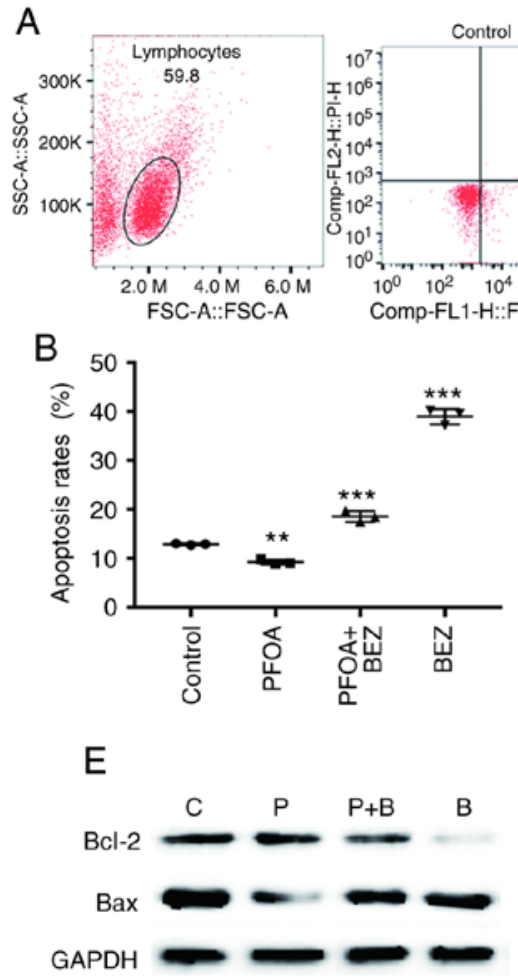

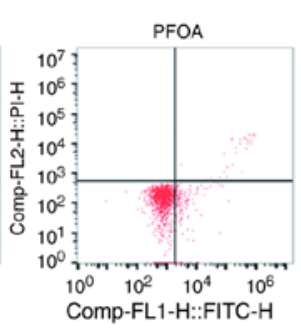

C

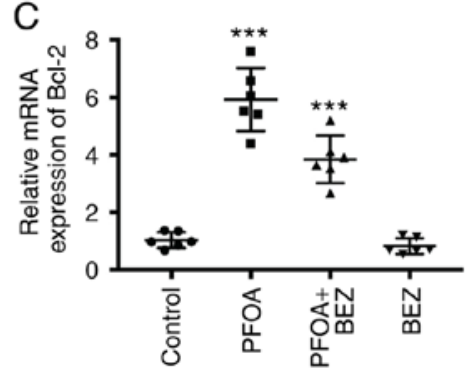

$\mathrm{F}$

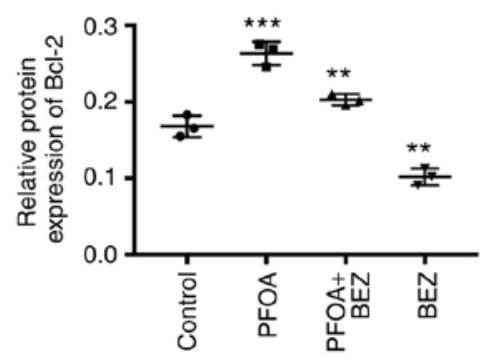

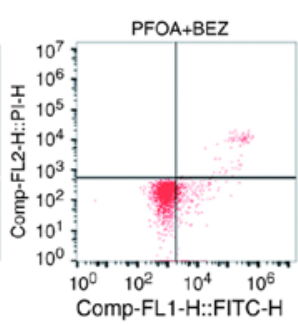
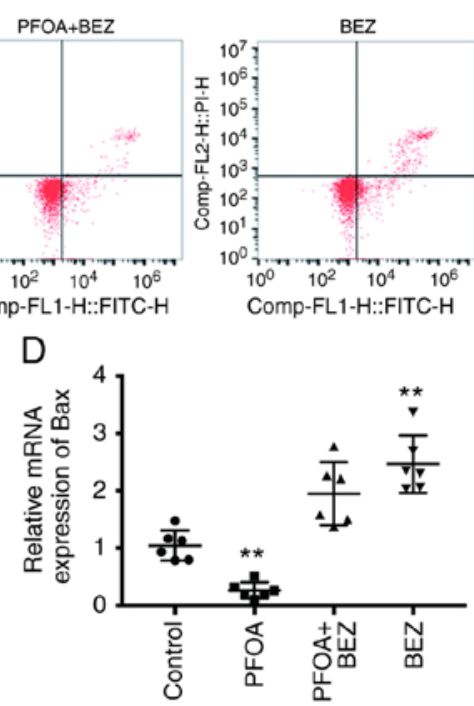

G

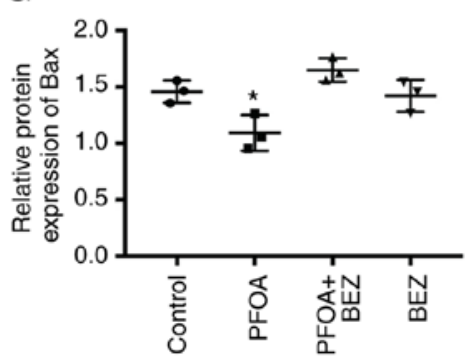

Figure 3. PFOA inhibits RD cell apoptosis. (A) Flow cytometry for evaluation of Annexin V FITC/PI-stained RD cells was performed $72 \mathrm{~h}$ after PBS, PFOA, PFOA + BEZ235, and BEZ235 treatment. (B) Cell apoptotic rates were statistically analyzed. The lower left quadrant represents intact viable cells (Annexin-FITC and PI-negative). The lower right quadrant represents early apoptotic cells (Annexin V-FITC-positive and PI-negative). The upper right region represents late apoptotic cells or secondary necrotic cells (Annexin-FITC- and PI-positive). Expression levels of (C) Bcl-2 and (D) Bax were analyzed by quantitative PCR in the PBS, PFOA, PFOA + BEZ235, and BEZ235-treated RD cells. (E) Western blotting and quantification of (F) Bcl-2 and (G) Bax band densities. Data are presented as the mean $\pm \mathrm{SD} .{ }^{*} \mathrm{P}<0.05,{ }^{* * *} \mathrm{P}<0.01$ and ${ }^{* * *} \mathrm{P}<0.001$ vs. control (PBS-treated). Data represent three independent experiments. PFOA, perfluorooctanoic acid; PBS, phosphate-buffered saline; BEZ, BEZ235; P+B, PFOA + BEZ235; C, control; PI, propidium iodide. 

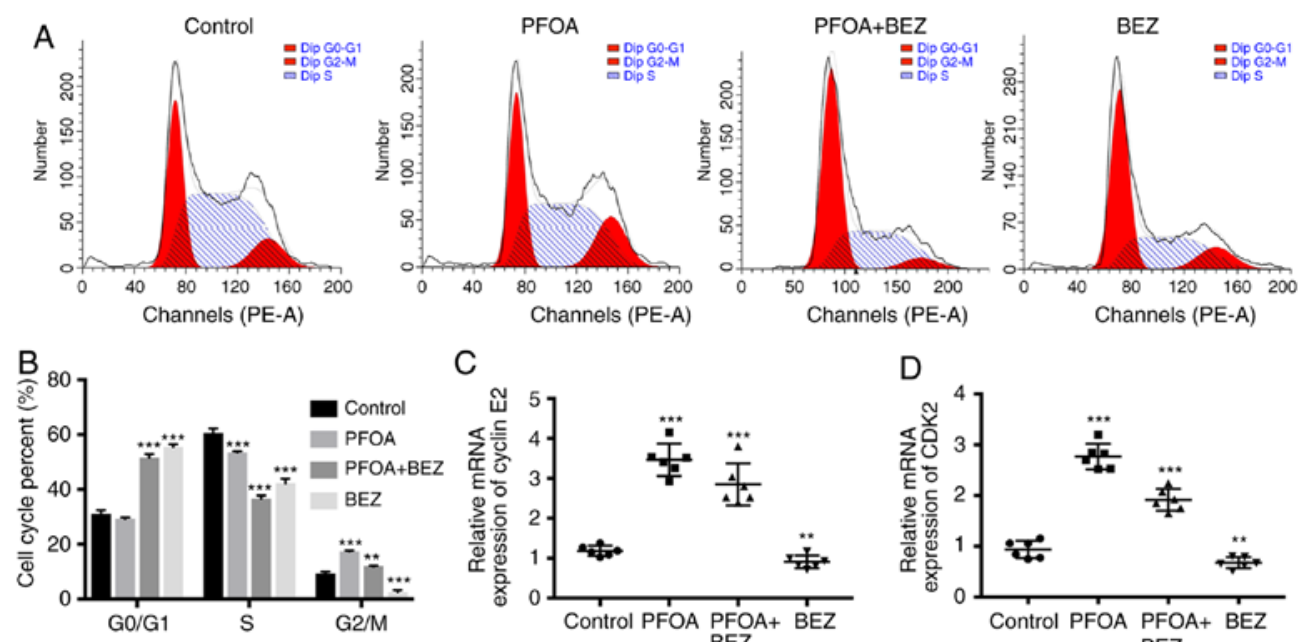

C
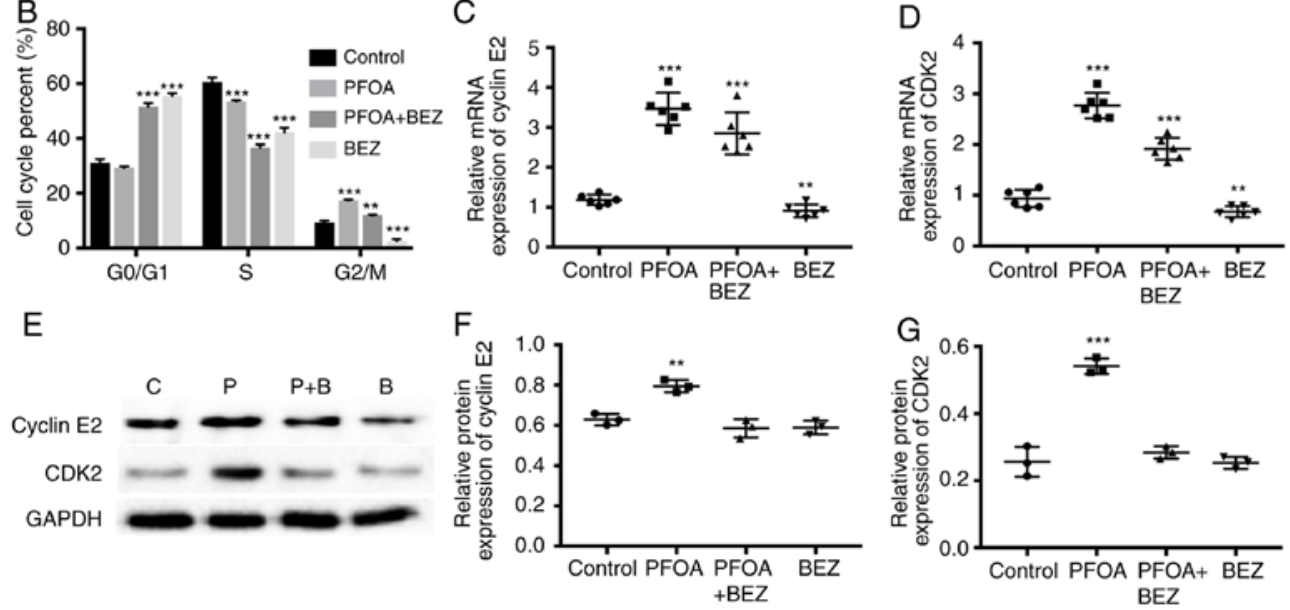

Figure 4. Effect of PFOA on RD cell cycle. (A) RD cells were treated with PBS, PFOA, PFOA + BEZ235, and BEZ235 for $72 \mathrm{~h}$, and the proportion of cells in each cell cycle phase was detected by flow cytometry. (B) Flow cytometry results showed that PFOA-treated RD cells had an increased proportion of cells in the G1/G2 phase. PFOA elicited the mRNA expression of (C) cyclin E2 and (D) CDK2. (E) Western blotting showed that PFOA also increased the protein expression of (F) cyclin E2 and (G) CDK2 in RD cells. No effects on the expression of p27, p21 or p53 were observed. Data are presented as the mean \pm SD. ${ }^{* *} \mathrm{P}<0.01$ and ${ }^{* * *} \mathrm{P}<0.001$ vs. control (PBS-treated). PFOA, perfluorooctanoic acid; PBS, phosphate-buffered saline; BEZ, BEZ235; P+B, PFOA + BEZ235; CDK2, cyclin-dependent kinase 2.
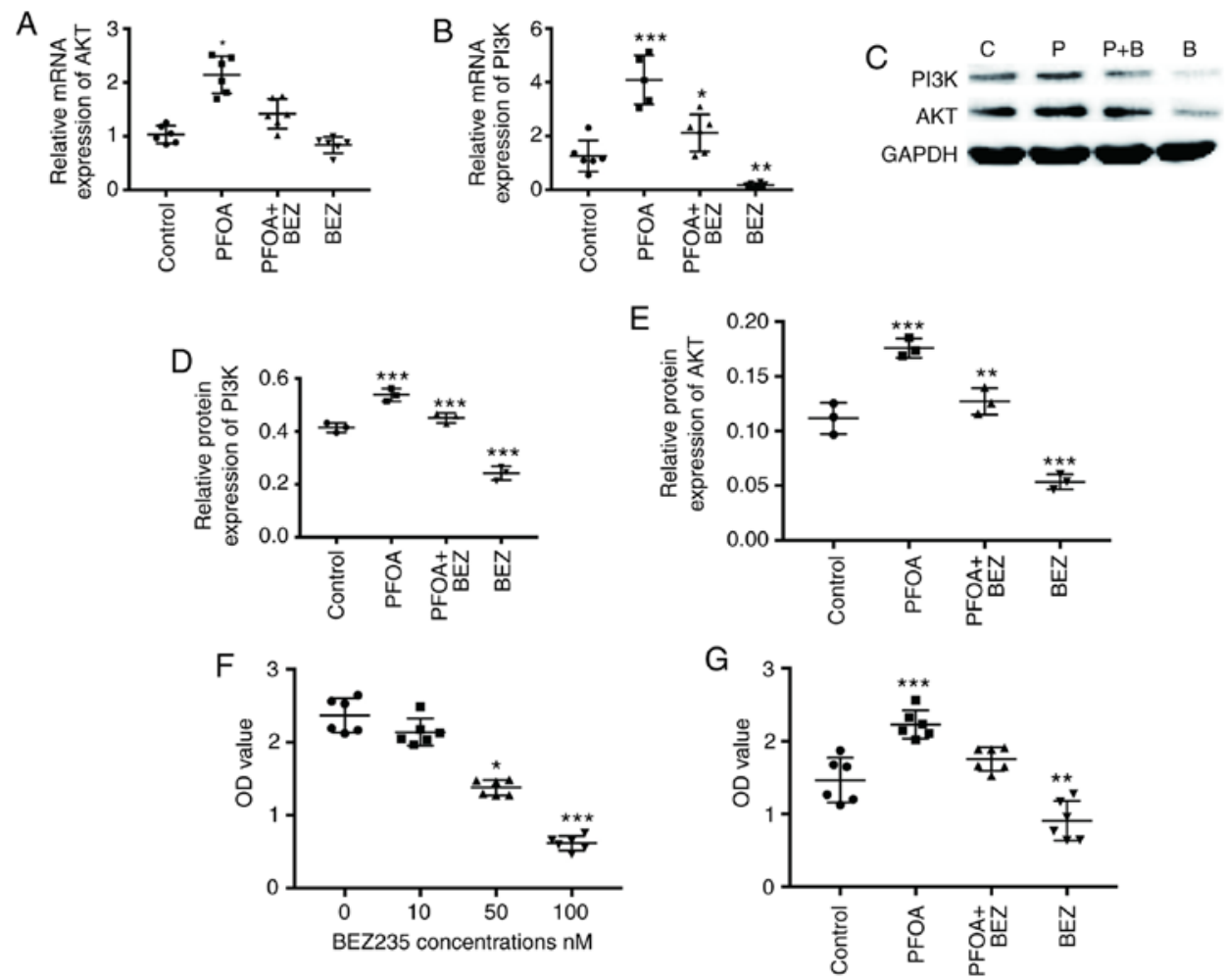

Figure 5. PFOA impacts the RD PI3K/AKT signaling pathway. RD cells were treated with PBS, PFOA, PFOA + BEZ235, and BEZ235 for $72 \mathrm{~h}$. The mRNA expression levels of (A) AKT and (B) PI3K were determined by quantitative PCR analysis. (C) Western blotting was performed and the protein levels of (D) PI3K and (E) AKT were determined. (F) CCK-8 assay showing RD cells treated with different concentrations of BEZ235 for $72 \mathrm{~h}$. (G) CCK-8 assay showing RD cells treated with PBS, PFOA, PFOA + BEZ235, and BEZ235 for $72 \mathrm{~h}$, Data are presented as the mean $\pm \mathrm{SD}$. ${ }^{*} \mathrm{P}<0.05,{ }^{* * *} \mathrm{P}<0.01$ and ${ }^{* * * *} \mathrm{P}<0.001$ vs. control (PBS-treated). PFOA, perfluorooctanoic acid; PI3K, phosphatidylinositol-3 kinase; AKT, protein kinase B; PBS, phosphate-buffered saline; BEZ, BEZ235; P+B, PFOA + BEZ235; CCK-8, Cell Counting Kit-8. 

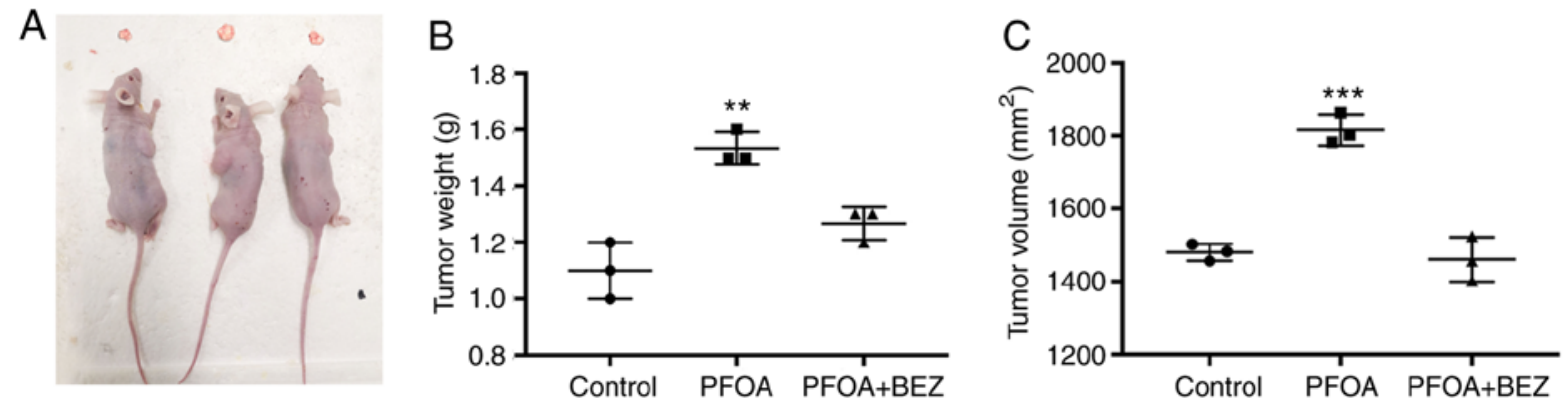

Figure 6. PFOA promotes tumor growth by activating the PI3K/AKT signaling pathway. (A) Representative images of tumor morphology 30 days after PBS, PFOA, and PFOA + BEZ235 treatments. (B) Tumor volume comparison. (C) Tumor weight comparison. Data are presented as the mean \pm SD. ${ }^{* *} \mathrm{P}<0.01$ and ${ }^{* * * * *} \mathrm{P}<0.001$ vs. control (PBS-treated). PFOA, perfluorooctanoic acid; PBS, phosphate-buffered saline; BEZ, BEZ235.

RD cell proliferation and inhibits apoptosis by activating the PI3K/AKT signaling pathway. Based on this, RD cells were used to construct a tumor model to measure whether PFOA can promote tumor progression in vivo and investigate whether PFOA has an impact on the tumor PI3K/AKT signaling pathway. Compared with measurements in the PBS control group, tumor size and weight were found to significantly increase following PFOA administration. Subsequently, tumor development was inhibited following BEZ235 administration (Fig. 6A-C).

\section{Discussion}

RMS is a type of tumor mainly derived from myogenic lineages and is thus a pediatric tumor (25), being the most frequent soft tissue tumor of childhood under the age of 5 years. Our previous study initially showed that PFOA can promote the migration and invasion of RD cells. Other studies have shown that PFOA exposure is involved in the tumor initiation process and potentially associated with DNA damage, increased oxidative stress and the development of several diseases, including cardiovascular, cerebrovascular and neoplastic disease $(2,3)$. Additionally, perfluorooctane sulfonate (PFOS) can promote MCF-10A breast epithelial cell proliferation by regulating cell cycle proteins and accelerating the cell cycle process (26). Although PFOS and PFOA are per- and polyfluoroalkyl substances which share structural and functional properties, they have different toxicological effects (27). The experiments performed in the present study demonstrated that PFOA promoted RD cell proliferation by regulating different cell cycle-related proteins. PFOA exposure induced RD cell proliferation and upregulated the cyclin E2 and CDK2 levels. PFOA induced RD cell migration and invasion, suggesting that it may induce normal skeletal muscle cells to transform into neoplastic cells.

Malignant tumors are characterized by their endless replication and cell circulation ability. This can occur at multiple levels, including in one or several proteins involved in cell cycle control and progression. As acknowledged, the most important step in tumor development is an excessive G-S phase. Evidence shows that cyclin E2 is a cyclin E family member potentially implicated in the G0/G1 to $S$ transition by CDK2 binding and $\mathrm{Rb}$ protein phosphorylation (16,28). Cyclin E-CDK2 is considered an essential and master regulator of cell cycle progression from the $\mathrm{G} 1$ to $\mathrm{S}$ phase (28). The results of the present study show that PFOA exposure increased cyclin E2 and CDK2 at the mRNA and protein levels. This may explain how PFOA promotes RD cell proliferation. Experiments on RD cells showed that CDK and cyclin regulation significantly inhibited cell proliferation (29). These results support the hypothesis that RD cell proliferation is elicited by cyclin E-CDK2 induction.

Two major CKI families are implicated in cell cycle regulation. One is the Cip/kip family (including p27 and p21), which may inhibit cyclin E-CDK (30). The downregulation or inactivation of p27 and p21, which normally cause G1 arrest, leads to abnormal cell cycle regulation, increases cell proliferation and causes malignant tumor formation (31). The P53 negative cell cycle regulator is mutated in several human tumors. Activation of the expression of p21 may inhibit cell cycle progression and control cell cycle at the apoptotic stage (32). A study on A2780 ovarian cells showed that p21 not only directly inhibited the activity of CDK but also increased the level of p27 by stabilizing p27 protein (33). However, the desired results were not obtained using the PI staining method to detect the proportion of cells in the three cell cycle phases. RD cell exposure to PFOA showed that cyclin E2 and CDK2 increased at the mRNA level, whereas no changes in p27, p21 or p53 were observed. Further investigation of the effects of PFOA on cell cycle gene and protein alterations in RD cells are required in order to gain further insights into its respective mechanism of action.

The metastatic process of tumor cells is complex, with invasion and migration being key steps. However, EMT is essential for malignant tumor cells to acquire invasion and migration ability. EMT is acknowledged as a complex cellular mechanism, associated with invasion and metastatic progression in various cancer cells. E-cadherin is an important epithelial marker and EMT-initiating factor, with EMT being activated when the expression of E-cadherin is downregulated, inhibited or lost (34). Although decitabine can induce the expression of E-cadherin, E-cadherin was not detected at the mRNA or protein levels in the present study. It was found that PFOA exposure increased the expression of vimentin and SGK1 in RD cells, suggesting that PFOA may elicit EMT. Vimentin is a typical EMT marker and a conserved $57-\mathrm{kD}$ protein, expressed in several mesenchymal cells (35) and overexpressed in epithelial tumors, positively correlating with tumor growth and invasion acceleration and with prognosis. SGK1 is a tumor-promoting gene with 
elevated expression in several malignancies, including prostate (36), gastric (37) and breast (38) cancer. Studies have suggested that SGK1 can promote metastases formation and it has been shown to serve a key role in promoting EMT in colorectal (39) and prostate (10) cancer. Therefore, it was crucial to investigate whether PFOA promoted RD cell migration and invasion in the present study. PFOA was shown to promote RD cell migration and invasion in wound healing and Transwell assays. PFOA may increase the expression of vimentin and SGK1 at the mRNA and protein levels.

Apoptosis refers to programmed cell death, and defects in this process can cause cancer or autoimmunity, whereas enhanced apoptosis may lead to degenerative diseases (40). The antiapoptotic protein $\mathrm{Bcl}-2$ may help tumor cells resist apoptosis, whereas the apoptotic protein Bax may elicit tumor cell apoptosis. Bcl-2 and Bax are present in the mitochondria and form a heterodimer. The overexpression of anti-apoptotic Bcl-2 or Bcl-xL occurs in $>50 \%$ of cancer cases (41). Bax directly affects apoptosis, being one of the most well-known downstream p53 transcriptional targets. P53 is able to inhibit the anti-apoptotic function of Bcl-2 and Bcl-xL on mitochondria during apoptosis (42). In the present study, PFOA exposure inhibited the expression of Bax and elicited the expression of Bcl-2 at the mRNA and protein levels.

In the present study, PFOA exposure promoted EMT and inhibited apoptosis. As recognized, the PI3K/AKT pathway serves an important role in cell growth by inhibiting apoptosis in several types of cancer $(43,44)$. PI3K modulates signaling pathways implicated in cell growth, apoptosis, or both, which may modulate the activity of AKT. Activating AKT may induce cell cycle progression, survival and migration through the phosphorylation of certain physiological factors. It has been reported that the activation of PI3K and AKT may lead to ovarian, thyroid, pancreatic and breast cancer (45). Based on these findings, using RT-qPCR and western blot analyses, the present study showed that PFOA increased the expression of PI3K and AKT. The results suggest that PFOA may enhance cell migration, invasion and proliferation and inhibit apoptosis through activation of the PI3K/AKT signaling pathway.

Further experiments were conducted to confirm this hypothesis. BEZ235, the PI3K inhibitor, reduced PFOA-induced proliferation, with the levels of formazan production significantly lower than those in RD cells exposed to PFOA alone. PFOA exposure affected cell proliferation through PI3K regulation of the cell cycle; treatment with BEZ235 and PFOA downregulated the mRNA expression levels of cyclin E2 and CKD2 in RD cells compared with those following treatment with PFOA alone. In the wound healing and Transwell invasion assays, the cells treated with BEZ235 and PFOA significantly reduced RD cells' migration and invasion compared with that in cells treated with PFOA alone. PFOA also promoted the expression of vimentin and SGK1, as determined by RT-qPCR and western blot assays. Although the expression of E-cadherin was not detected at the mRNA or proteins levels, further investigations are warranted to elucidate why. Treatment with BEZ235 and PFOA reversed the single PFOA treatment-induced upregu- lation of vimentin and SGK1. Similar results were found for the apoptotic Bcl-2 and Bax proteins. The mRNA and protein expression levels of Bax were higher following BEZ235 and PFOA treatment those that following treatment with PFOA alone, and the mRNA and protein expression levels of Bcl-2 were lower following treatment with BEZ235 and PFOA compared with those treated with to PFOA only. These results indicated that PFOA treatment induces EMT and inhibits apoptosis in RD cells, also requiring activation of the PI3K/AKT signaling pathway.

Taken together, the results of the present study suggest that PFOA regulates RD cell proliferation, migration, invasion and apoptosis through activation of the PI3K/AKT signaling pathway, potentially eliciting tumorigenesis. The in vivo experiments allowed analysis of the effects of PFOA on the tumors, showing that it led to increased tumor volume and weight. In future investigations, further in vivo experiments are to be developed to investigate the effects of PFOA on the tumor and on the tumorigenic mechanism, through analysis of cell cycle, EMT and apoptosis. A clearer understanding of the role of PFOA in tumorigenesis can assist in preventing and treating tumors elicited by this agent.

\section{Acknowledgements}

Not applicable.

\section{Funding}

The present study was supported by the National Natural Science Foundation Of China (grant no. 61827806).

\section{Availability of data and materials}

The datasets used during the present study are available from the corresponding anthor upon reasonable request.

\section{Authors' contributions}

Conceptualization of the study was achieved by QZ and CW, the research methodology was designed by QZ, JW, CC, YK, HY, JD and CW. Formal analysis of the data was conducted by QZ and YK. Funding acquisition was accomplished by CW. Project administration was carried out by $\mathrm{CW}$, and study resources were obtained by QZ and CW. Software analysis of data and figures were conducted by QZ, YK, JW and CC, supervision of the research was conducted by $\mathrm{XN}$ and $\mathrm{CW}$. Writing of the original draft was undertaken by QZ, JW and $\mathrm{CC}$, and writing, review and editing of the manuscript were carried out by QZ, JD, YS, XW and CW. All authors read and approved the manuscript and agree to be accountable for all aspects of the research in ensuring that the accuracy or integrity of any part of the work are appropriately investigated and resolved.

\section{Ethics approval and consent to participate}

All animal treatments were approved by the Ethics Committee of the Experimental Animal Center and by the Chinese Academy of Military Medical Sciences (permit 
no. SCXK-2015-0002), in accordance with the guiding principles for the use of animals in toxicology, adopted by the Society of Toxicology in 1989.

\section{Patient consent for publication}

Not applicable.

\section{Competing interests}

The authors declare that they have no competing interests.

\section{References}

1. Bartell SM, Calafat AM, Lyu C, Kato K, Ryan PB and Steenland K: Rate of decline in serum PFOA concentrations after granular activated carbon filtration at two public water systems in Ohio and West Virginia. Environ Health Perspect 118: 222-228, 2010.

2. Shin HM, Vieira VM, Ryan PB, Steenland K and Bartell SM Retrospective exposure estimation and predicted versus observed serum perfluorooctanoic acid concentrations for participants in the C8 health project. Environ Health Perspect 119: 1760-1765, 2011.

3. Barry V, Winquist A and Steenland K: Perfluorooctanoic acid (PFOA) exposures and incident cancers among adults living near a chemical plant. Environ Health Perspect 121: 1313-1318, 2013.

4. Lau C, Anitole K, Hodes C, Lai D, Pfahles-Hutchens A and Seed J: Perfluoroalkyl acids: A review of monitoring and toxicological findings. Toxicol Sci 99: 366-394, 2007.

5. Pierozan P, Jerneren F and Karlsson O: Perfluorooctanoic acid (PFOA) exposure promotes proliferation, migration and invasion potential in human breast epithelial cells. Arch Toxicol 92: $1729-1739,2018$.

6. Wielsøe M, Kern P and Bonefeld-Jørgensen EC: Serum levels of environmental pollutants is a risk factor for breast cancer in Inuit: a case control study. Environ Health 16: 56, 2017.

7. Cha YH, Yook JI, Kim HS and Kim NH: Catabolic metabolism during cancer EMT. Arch Pharm Res 38: 313-320, 2015.

8. Natarajan J, Chandrashekar C and Radhakrishnan R: Critical biomarkers of epithelial-mesenchymal transition in the head and neck cancers. J Cancer Res Ther 10: 512-518, 2014.

9. Myong NH: Loss of E-cadherin and acquisition of vimentin in epithelial-mesenchymal transition are noble indicators of uterine cervix cancer progression. Korean J Pathol 46: 341-348, 2012.

10. Liu W, Wang X, Wang Y, Dai Y, Xie Y, Ping Y, Yin B, Yu P, Liu Z, Duan X, et al: SGK1 inhibition-induced autophagy impairs prostate cancer metastasis by reversing EMT. J Exp Clin Cancer Res 37: 73, 2018.

11. Jeanes A, Gottardi CJ and Yap AS: Cadherins and cancer: How does cadherin dysfunction promote tumor progression? Oncogene 27: 6920-6929, 2008.

12. Satelli A and Li S: Vimentin as a potential molecular target in cancer therapy or Vimentin, an overview and its potential as a molecular target for cancer therapy. Cell Mol Life Sci 68 : 3033-3046, 2011.

13. Ibrahim U, Saqib A, Mohammad F, Ding J, Salman B, Collado FK and Dhar M: Embryonal rhabdomyosarcoma of the cervix: A rare disease at an uncommon age. Cureus 9: e1864, 2017.

14. Mummery CL, van den Brink CE and de Laat SW: Commitment to differentiation induced by retinoic acid in P19 embryonal carcinoma cells is cell cycle dependent. Dev Biol 121: 10-19, 1987.

15. Filipczyk AA, Laslett AL, Mummery C and Pera MF: Differentiation is coupled to changes in the cell cycle regulatory apparatus of human embryonic stem cells. Stem Cell Res 1: 45-60, 2007.

16. Santamaria D and Ortega S: Cyclins and CDKS in development and cancer: Lessons from genetically modified mice. Front Biosci 11: 1164-1188, 2006.

17. Stead E, White J, Faast R, Conn S, Goldstone S, Rathjen J, Dhingra U, Rathjen P, Walker D and Dalton S: Pluripotent cell division cycles are driven by ectopic Cdk2, cyclin A/E and E2F activities. Oncogene 21: 8320-8333, 2002.

18. Courtney KD, Corcoran RB and Engelman JA: The PI3K pathway as drug target in human cancer. J Clin Oncol 28: 1075-1083, 2010.
19. Fruman DA and Rommel C: PI3K and cancer: Lessons, challenges and opportunities. Nat Rev Drug Discov 13: 140-156, 2014.

20. Meng X, Dong X, Wang W, Yang L, Zhang X, Li Y, Chen T, Ma H, Qi D and Su J: Natural borneol enhances paclitaxel-induced apoptosis of ESCC cells by inactivation of the PI3K/AKT. J Food Sci 83: 1436-1443, 2018.

21. Livak KJ and Schmittgen TD: Analysis of relative gene expression data using real-time quantitative PCR and the 2(-Delta Delta C(T)) method. Methods 25: 402-408, 2001.

22. Yan S, Wang J, Zhang $\mathrm{W}$ and Dai J: Circulating microRNA profiles altered in mice after $28 \mathrm{~d}$ exposure to perfluorooctanoic acid. Toxicol Lett 224: 24-31, 2014.

23. Yang F, Qian XJ, Qin W, Deng R, Wu XQ, Qin J, Feng GK and Zhu XF: Dual phosphoinositide 3-kinase/mammalian target of rapamycin inhibitor NVP-BEZ235 has a therapeutic potential and sensitizes cisplatin in nasopharyngeal carcinoma. PLoS One 8: e59879, 2013.

24. Ma Z, Liu X, Li F, Wang Y, Xu Y, Zhang M, Zhang X, Ying X and Zhang X: Perfluorooctanoic acid induces human Ishikawa endometrial cancer cell migration and invasion through activation of ERK/mTOR signaling. Oncotarget 7: 66558-66568, 2016.

25. Blum JM, Añó L, Li Z, Van Mater D, Bennett BD, Sachdeva M, Lagutina I, Zhang M, Mito JK, Dodd LG, et al: Distinct and overlapping sarcoma subtypes initiated from muscle stem and progenitor cells. Cell Rep 5: 933-940, 2013.

26. Pierozan $\mathrm{P}$ and Karlsson O: PFOS induces proliferation, cell-cycle progression, and malignant phenotype in human breast epithelial cells. Arch Toxicol 92: 705-716, 2018.

27. Tsuda S: Differential toxicity between perfluorooctane sulfonate (PFOS) and perfluorooctanoic acid (PFOA). J Toxicol Sci 41 (Special): SP27-SP36, 2016.

28. Hwang HC and Clurman BE: Cyclin E in normal and neoplastic cell cycles. Oncogene 24: 2776-2786, 2005.

29. Marampon F, Ciccarelli C and Zani BM: Down-regulation of c-Myc following MEK/ERK inhibition halts the expression of malignant phenotype in rhabdomyosarcoma and in non muscle-derived human tumors. Mol Cancer 5: 31, 2006.

30. Le Page C, Huntsman DG, Provencher DM and Mes-Masson AM: Predictive and prognostic protein biomarkers in epithelial ovarian cancer: Recommendation for future studies. Cancers (Basel) 2: 913-954, 2010.

31. Bali A, O'Brien PM, Edwards LS, Sutherland RL, Hacker NF and Henshall SM: Cyclin D1, p53, and p21Waf1/Cip1 expression is predictive of poor clinical outcome in serous epithelial ovarian cancer. Clin Cancer Res 10: 5168-5177, 2004.

32. Milde-Langosch K and Riethdorf S: Role of cell-cycle regulatory proteins in gynecological cancer. J Cell Physiol 196: 224-244, 2003.

33. He G, Kuang J, Huang Z, Koomen J, Kobayashi R, Khokhar AR and Siddik ZH: Upregulation of p27 and its inhibition of CDK2/cyclin E activity following DNA damage by a novel platinum agent are dependent on the expression of $\mathrm{p} 21$. Br J Cancer 95: 1514-1524, 2006.

34. Qin Y, Guo H, Tang B and Yang SM: The non-reverse transcriptase activity of the human telomerase reverse transcriptase promotes tumor progression (review). Int J Oncol 45: 525-531, 2014.

35. Satelli A and Li S: Vimentin in cancer and its potential as a molecular target for cancer therapy. Cell Mol Life Sci 68: 3033-3046, 2011.

36. Yao Y, Jiang Q, Jiang L, Wu J, Zhang Q, Wang J, Feng H and Zang P: Lnc-SGK1 induced by Helicobacter pylori infection and highsalt diet promote $\mathrm{Th} 2$ and Th17 differentiation in human gastric cancer by SGK1/Jun B signaling. Oncotarget 7: 20549-20560, 2016.

37. Szmulewitz RZ, Chung E, Al-Ahmadie H, Daniel S, Kocherginsky M, Razmaria A, Zagaja GP, Brendler CB, Stadler WM and Conzen SD: Serum/glucocorticoid-regulated kinase 1 expression in primary human prostate cancers. Prostate 72: 157-164, 2012.

38. Jo A, Yun HJ, Kim JY, Lim SC, Choi HJ, Kang BS, Choi BY and Choi HS: Prolyl isomerase PIN1 negatively regulates SGK1 stability to mediate tamoxifen resistance in breast cancer cells. Anticancer Res 35: 785-794, 2015.

39. Gulhati P, Bowen KA, Liu J, Stevens PD, Rychahou PG, Chen M, Lee EY, Weiss HL, O'Connor KL, Gao T and Evers BM: mTORC1 and mTORC2 regulate EMT, motility, and metastasis of colorectal cancer via RhoA and Rac1 signaling pathways. Cancer Res 71: 3246-3256, 2011. 
40. Hassan M, Watari H, AbuAlmaaty A, Ohba Y and Sakuragi N Apoptosis and molecular targeting therapy in cancer. Biomed Res Int 2014: 150845, 2014

41. Amundson SA, Myers TG, Scudiero D, Kitada S, Reed JC and Fornace AJ Jr: An informatics approach identifying markers of chemosensitivity in human cancer cell lines. Cancer Res 60: 6101-6110, 2000.

42. Mihara M, Erster S, Zaika A, Petrenko O, Chittenden T, Pancoska P and Moll UM: p53 has a direct apoptogenic role at the mitochondria. Mol Cell 11: 577-590, 2003.
43. Franke TF, Hornik CP, Segev L, Shostak GA and Sugimoto C: PI3K/Akt and apoptosis: Size matters. Oncogene 22: 8983-8998, 2003.

44. Cantley LC and Neel BG: New insights into tumor suppression: PTEN suppresses tumor formation by restraining the phosphoinositide 3-kinase/AKT pathway. Proc Natl Acad Sci USA 96: 4240-4245, 1999.

45. Blanco-Aparicio C, Renner O, Leal JF and Carnero A: PTEN, more than the AKT pathway. Carcinogenesis 28: 1379-1386, 2007. 